\title{
A Monte Carlo Analysis of the Thrust Imbalance for the Space Launch System Booster during Both the Ignition Transient and Steady State Operation
}

\author{
Winfred A. Foster, Jr. ${ }^{1}$ \\ Auburn University, Auburn, AL 36849 \\ Winston Crowder ${ }^{2}$ \\ Lockheed-Martin Corporation, Huntsville, $A L$ \\ Todd E. Steadman ${ }^{3}$ \\ National Aeronautics and Space Administration, Marshall Space Flight Center, AL
}

This paper presents the results of statistical analyses performed to predict the thrust imbalance between two solid rocket motor boosters to be used on the Space Launch System (SLS) vehicle. Two legacy internal ballistics codes developed for the Space Shuttle program were coupled with a Monte Carlo analysis code to determine a thrust imbalance envelope for the SLS vehicle based on the performance of $\mathbf{1 0 0 0}$ motor pairs. Thirty three variables which could impact the performance of the motors during the ignition transient and thirty eight variables which could impact the performance of the motors during steady state operation of the motor were identified and treated as statistical variables for the analyses. The effects of motor to motor variation as well as variations between motors of a single pair were included in the analyses. The statistical variations of the variables were defined based on data provided by NASA's Marshall Space Flight Center for the upgraded five segment booster and from the Space Shuttle booster when appropriate. The results obtained for the statistical envelope are compared with the design specification thrust imbalance limits for the SLS launch vehicle.

\section{Introduction}

$\mathrm{T}$ he knowledge of the difference in thrust at any point in time between two motors of pair operating on the same vehicle, referred to in this work as thrust imbalance, is necessary for predicting the loads on the vehicle and launch pad during motor ignition and for vehicle loads and control requirements during flight. This work uses a Monte Carlo statistical method approach developed and verified for the Space Shuttle boosters by Sforzini and Foster in Refs. 1 and 2 to develop statistical envelopes for the thrust imbalance versus time during both ignition transient and steady state motor operation of the Space Launch System (SLS) vehicle. The analysis is done in two parts using two different computer codes, one for the ignition transient and one for the steady state operation of the motors. The code chosen for the ignition transient was developed by Caveny and Kuo in Refs. 3 and 4 and the code used for the steady state operation was developed in Refs. 1 and 2. The codes were chosen because of their proven ability to simulate the internal ballistic performance characteristics in an accurate and efficient manner. The need to analyze a large number of motors, of the order of 2,000 individual motors in a reasonable amount of time made these two codes logical choices. The details of the internal ballistics codes used are well documented in the above cited references and are not being repeated in this paper. A MATLAB shell program was created and used to coordinate the user input files, program execution, output text files and plotting routines. The use of the programs in the MATLAB environment is described in Ref. 5.

\footnotetext{
${ }^{1}$ Professor, Aerospace Engineering Department, 211 Davis Hall, Associate Fellow

2 Insert Job Title, Department Name, Address/Mail Stop, and AIAA Member Grade for second author.

${ }^{3}$ Team Lead, Solid Motor Design and Analysis Team,
} 


\section{Ignition Transient Thrust Imbalance Analysis}

The Monte Carlo method described in Ref. 1 was coupled with the one-dimensional internal ballistics ignition transient code developed in Refs. 3 and 4. This code was chosen since it is still currently being used by NASA/MSFC personnel and other organizations for ignition transient predictions and because it was readily adaptable to the Monte Carlo technique. A more complete discussion of the utilization of the computer code will be given later in this section.

The Monte Carlo analysis of the ignition transient thrust imbalance used 33 selected variables for the ignition transient code. These variables are presented in in Table II.1 below.

Table II.1 Monte Carlo Analysis Ignition Transient Variables.

\begin{tabular}{|l|l|}
\hline Variable Name & Variable Definition \\
\hline TPI & initial propellant grain temperature \\
\hline AT & nozzle throat area \\
\hline XP & location where propellant begins \\
\hline XG & aft end of propellant \\
\hline XE & end of flow passage \\
\hline GAMA & ratio of specific heats \\
\hline W & molecular weight of combustion gases \\
\hline TIGN & igniter gas mean temperature \\
\hline TFREF & reference adiabatic flame temperature \\
\hline RUFSUR & port wall roughness \\
\hline FKPR & propellant thermal conductivity \\
\hline ROPR & propellant density \\
\hline CPR & propellant specific heat \\
\hline TOREF & reference propellant temperature \\
\hline SIGP & temperature sensitivity of burning rate a constant pressure \\
\hline TPSCRI & surface ignition temperature \\
\hline RREF & reference burning rate \\
\hline PREF & propellant property reference temperature \\
\hline BREXP & burning rate exponent \\
\hline EBC & Robillard-Lenoir constant \\
\hline EBEX & Robillard-Lenoir constant \\
\hline DE & diameter of the nozzle exit plane \\
\hline CM & nozzle thrust loss coefficient \\
\hline EROAT & nozzle erosion parameter \\
\hline EROEXP & nozzle erosion parameter \\
\hline ALFAD & nozzle divergence half-angle \\
\hline TPSHFT & reference PMBT difference between motors of a single pair \\
\hline BRSHFT & reference burning rate shift between motors of a single pair \\
\hline ATSHFT & reference throat area shift between motors of a single pair \\
\hline DPSHFT & reference propellant density shift between motors of a single pair \\
\hline DESHFT & reference exit diameter shift between motors of a single pair \\
\hline ETSHFT & reference throat erosion rate shift between motors of a single pair \\
\hline SHFTMI & reference $\Delta t$ time shift in mass addition versus time from the igniter \\
\hline
\end{tabular}


Some of the variables listed in Table II.1 were held constant for the present analysis, but can be used if their statistical variation properties are known. As can be seen from the variable definitions above, there are motor to motor variations and variations within a single pair of motors. Variations within a pair are identified by SHFT either before or after the variable name. For example BRSHFT is the within pair variation of the burn rate RREF. The analysis consisted of selecting input parameters for 2000 5-segment SLS solid rocket motors or 1000 motor pairs. The variations between motors of a pair were defined for what was referred to as the odd and even numbered motors in that pair. Specifically, the odd numbered motor was considered the base for the pair and the motor to motor variations were imposed on the even numbered motor relative to the odd numbered motor. Based on the Monte Carlo variable selection process, input files for the 2000 individual motors were created. These input files were then analyzed sequentially and individually in the internal ballistics ignition transient code in the internal ballistics ignition transient code in the internal ballistics ignition transient code to determine the thrust time trace for each motor. The results for the odd and even motors were stored separately and the thrust imbalance versus time was calculated for each pair of motors.

The results presented below are for a propellant mean bulk temperature (PMBT) selected randomly between $40^{\circ} \mathrm{F}$ and $90^{\circ} \mathrm{F}$ and a within pair variation given by TGSHFT. The burn rate reference temperature was $60^{\circ} \mathrm{F}$. The thrust imbalance versus time data was calculated for each pair and the thrust imbalance for analyzed statistically at selected time points. The number of time points selected was the results of this analysis were the mean and standard deviation for the thrust imbalance at each time slice chosen. Based on this data a prediction of the K-sigma limit about a zero mean value envelope was constructed as a function time. For 1000 pairs, $\mathrm{K}$ was chosen to be $3.4725^{5}$. This value of $\mathrm{K}$ is for a probability of $99 \%$ that $99.9 \%$ will be included between the mean value and $+/-\mathrm{K}$ times the standard deviation. This envelope was then compared to the design thrust imbalance limits for a pair of motors during the ignition transient as shown in Fig. II.1. 


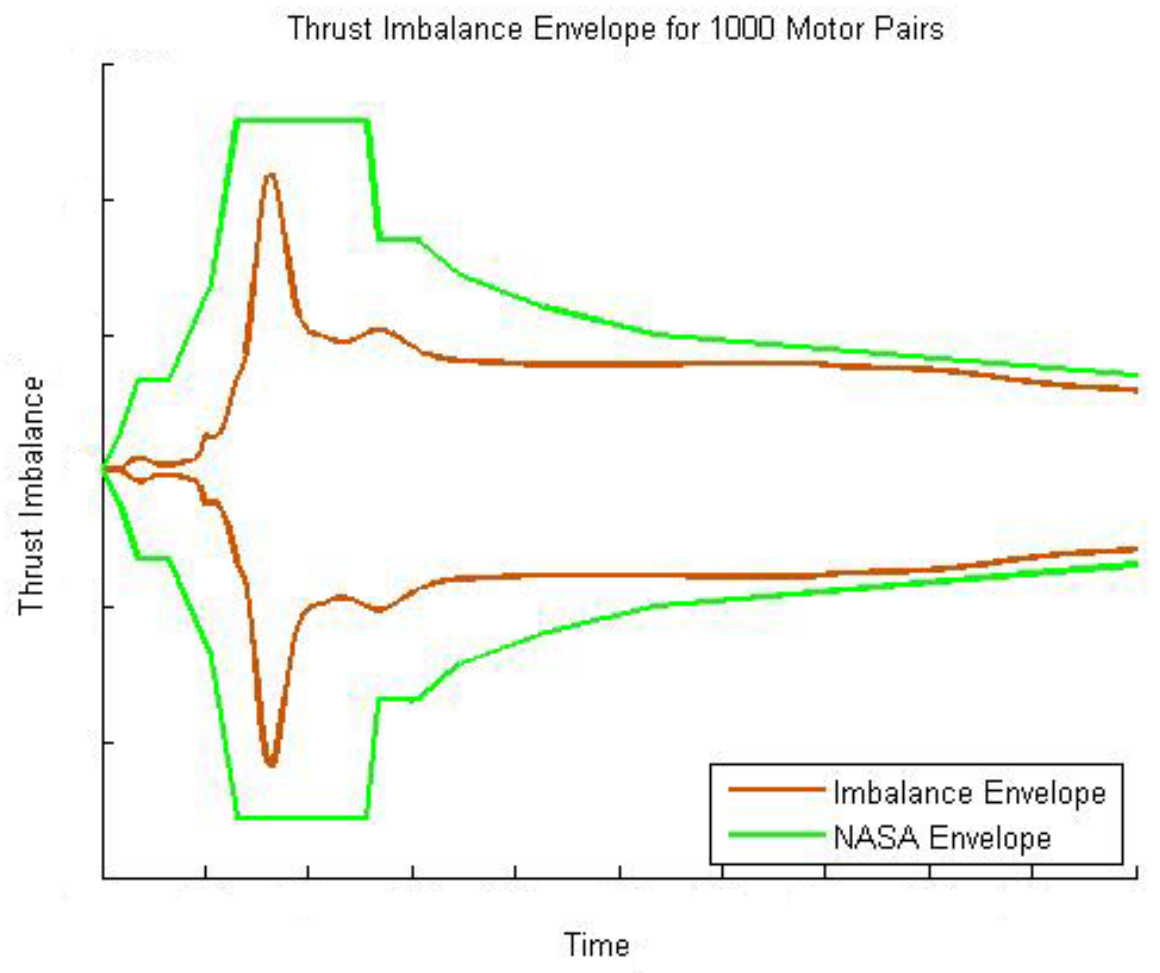

Figure II-1. Steady state thrust imbalance envelopes $\left(\mathrm{PMBT}\right.$ mean $=40^{\circ}-90^{\circ} \mathrm{F}$ and $\left.\mathrm{K}=3.472\right)$.

The thrust imbalance data was also analyzed to determine the mean value and standard deviation of the maximum absolute value of the thrust imbalance and the time at which it occurred for specified time intervals during the ignition transient. In addition to the plot of the imbalance envelope, the results for all of the motors were available for plotting, both together and individually. Fig. II.2 presents a plot of plus or minus the absolute value of the thrust imbalance versus time for 1000 motor pairs compared to the envelopes shown in Fig. II.1. The results shown above indicate that for the statistical variations expected in the selected internal ballistic performance parameters that the resulting thrust imbalance between the two motors will meet the current design criteria limits. Furthermore, the thrust imbalance envelopes predicted by the Monte Carlo analysis agree quite well with the current design envelope with regard to the time dependent variation in thrust imbalance during the ignition transient for the SLS motors. It should be pointed out that the NASA thrust imbalance envelopes are valid for any odd motor of a pair having a PMBT between $40^{\circ} \mathrm{F}$ and $90^{\circ} \mathrm{F}$ with the even motor being constrained to be within the allowable temperature difference between motors of a single pair. We point this out because the NASA envelopes shown later in this paper for the steady state thrust imbalance have been scaled to eliminate the effects of PMBT on the thrust imbalance versus time. We will say more about this later in the paper. 


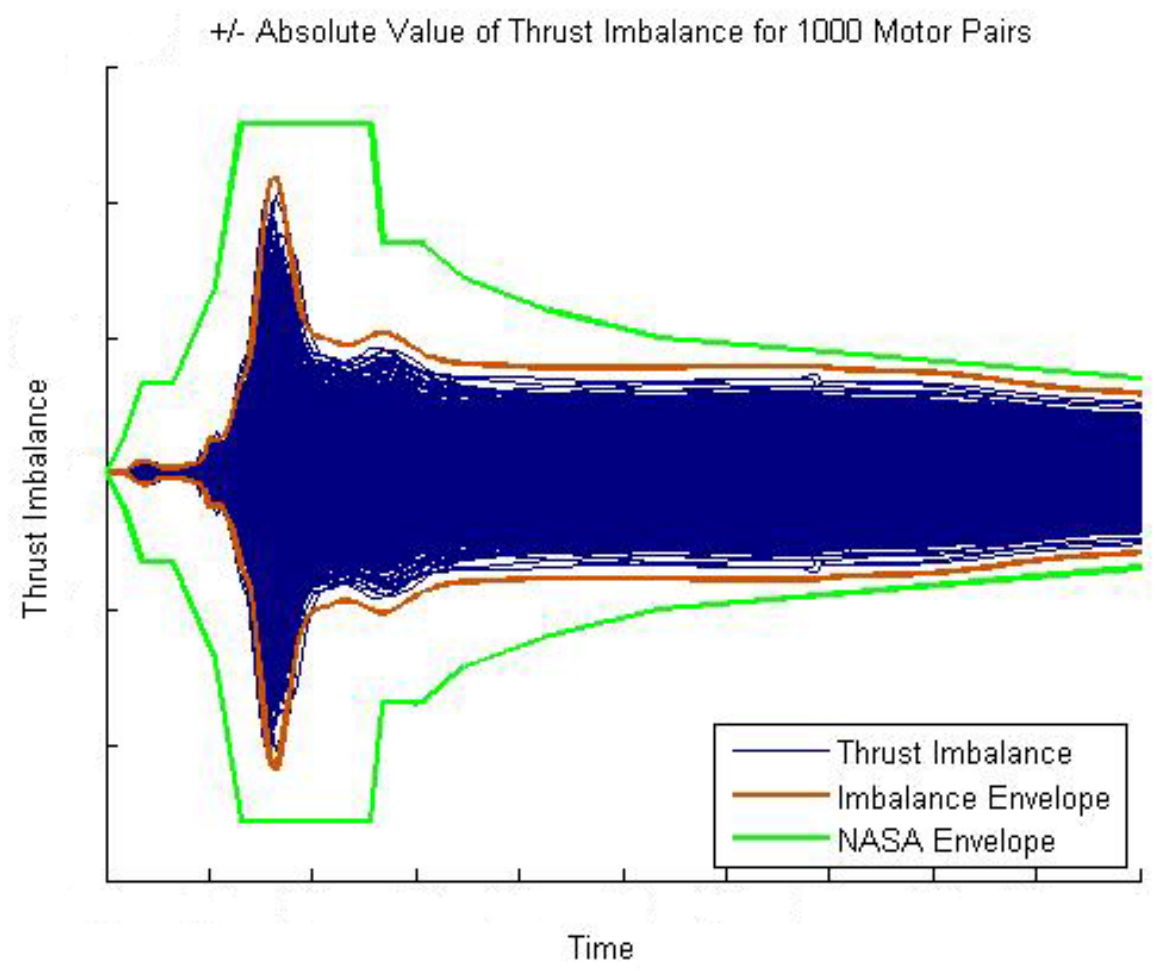

Figure II.2. +/- Absolute value of the thrust imbalance during the ignition transient ( $P$ MBT mean $=40^{\circ}-90^{\circ} \mathrm{F}$ and $\mathrm{K}=3.472$ ).

Fig. II. 3 shows the thrust time traces for 2000 motors during the ignition transient. Figs. II.4 and II.5 show the thrust time traces for the odd and even numbered motors respectively. These figures show the variability in thrust between the individual motors. To illustrate one feature of the possible data reduction capability contained in the codes Fig. II.6 shows a typical thrust imbalance trace for a single motor pair compared to the thrust imbalance envelopes and Fig. II.7 compares the thrust time traces for the same pair of motors. These latter two plots can be useful because they allows the analyst to locate motor pairs where the thrust imbalance may be high and then to look at the performance parameters for that particular pair to evaluate what may have caused the high imbalance. 


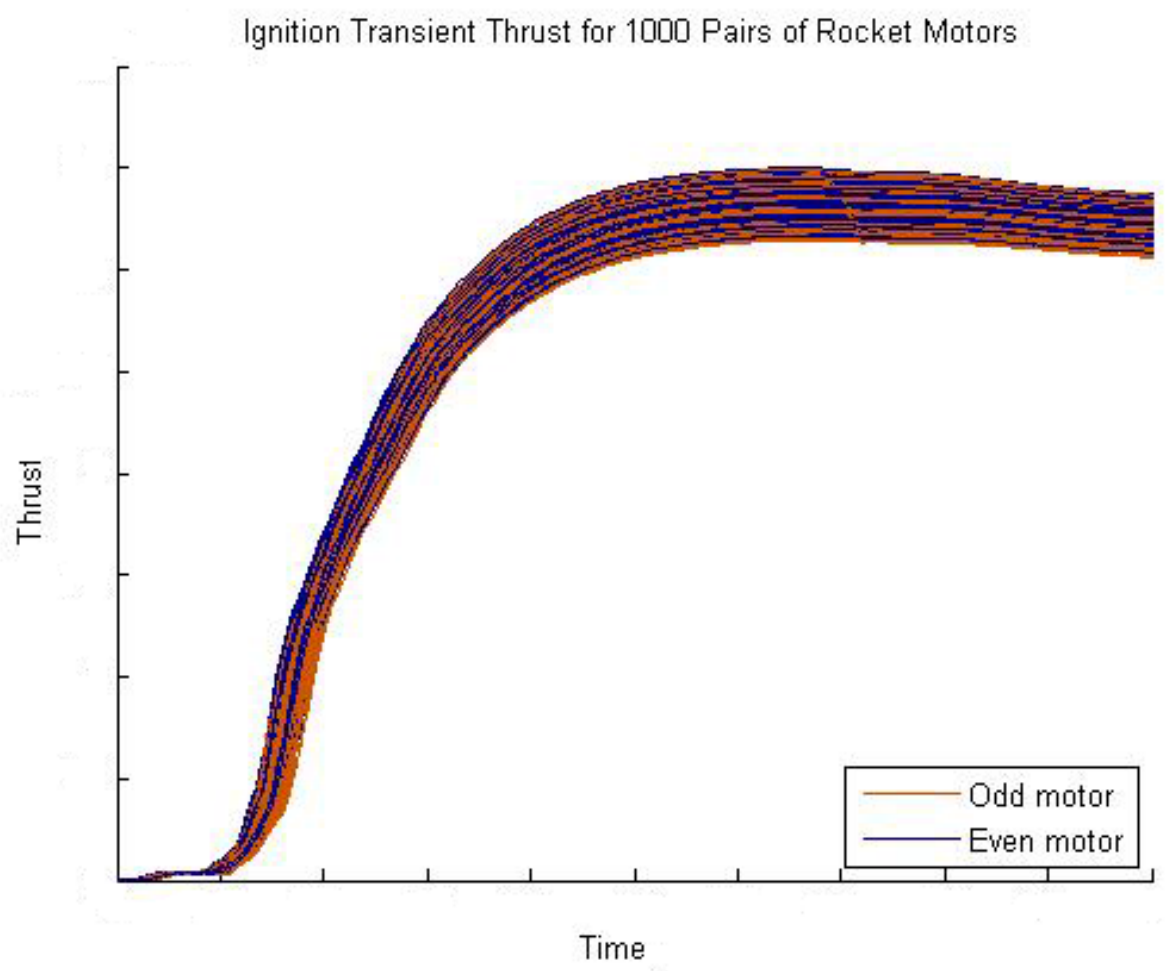

Figure II.3. Thrust time traces for $\mathbf{2 0 0 0}$ motors during ignition transient $\left(\mathrm{PMBT}\right.$ mean $\left.=40^{\circ}-\mathbf{9 0}^{\circ} \mathrm{F}\right)$

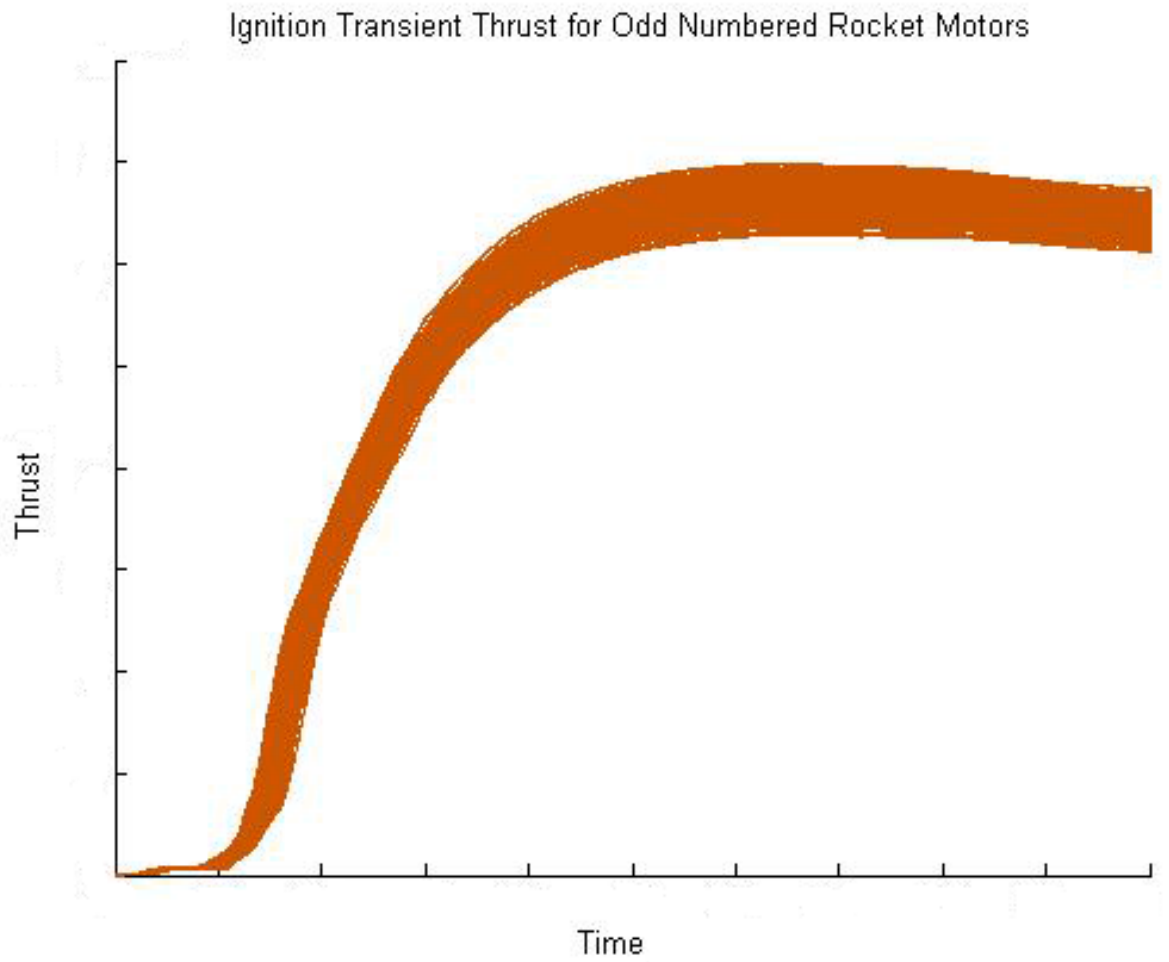

Figure II.4. Thrust time traces for odd numbered motors $\left(\mathrm{PMBT}\right.$ mean $\left.=\mathbf{4 0}^{\circ}-\mathbf{9 0}^{\circ} \mathrm{F}\right)$.

6

American Institute of Aeronautics and Astronautics 
4

Ignition Transient Thrust for Even Numbered Rocket Motors

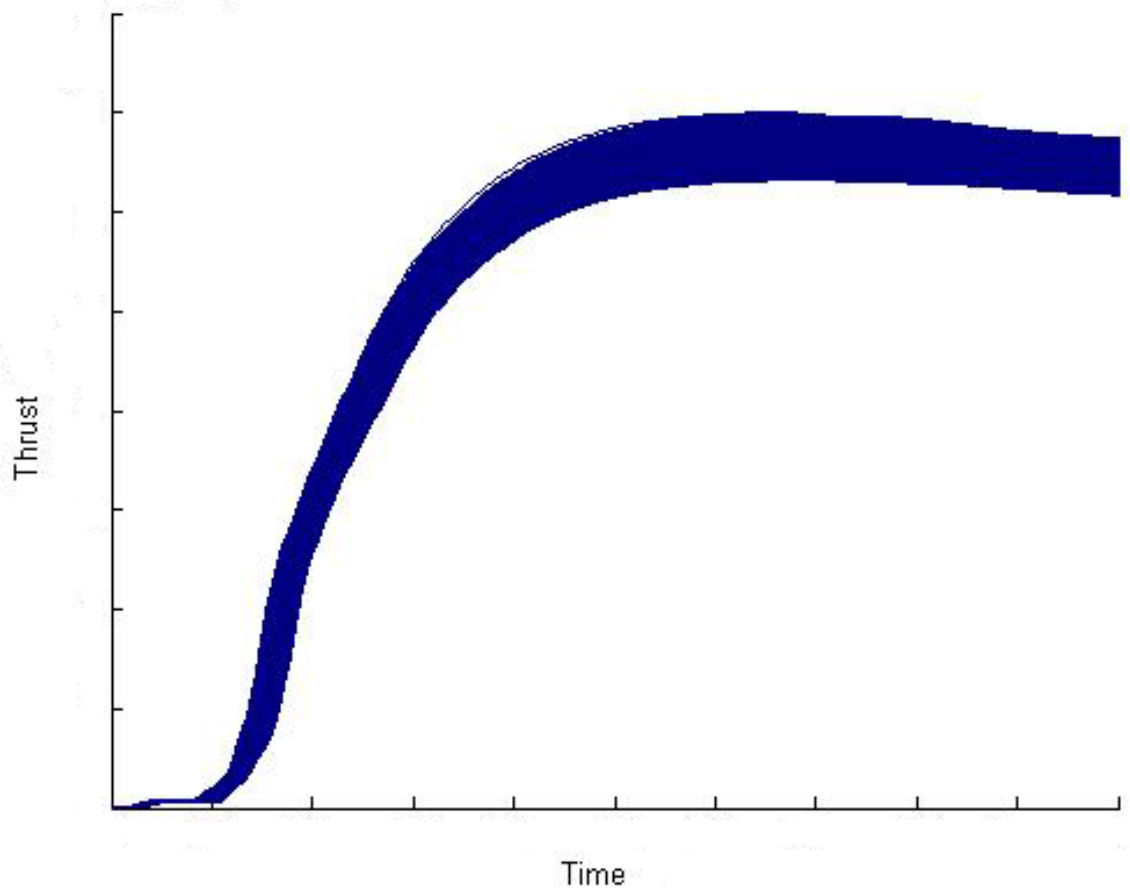

Figure II.5. Thrust time traces for even numbered motors $\left(\mathrm{PMBT}\right.$ mean $\left.=\mathbf{4 0}^{\circ}-\mathbf{9 0}^{\circ} \mathrm{F}\right)$.

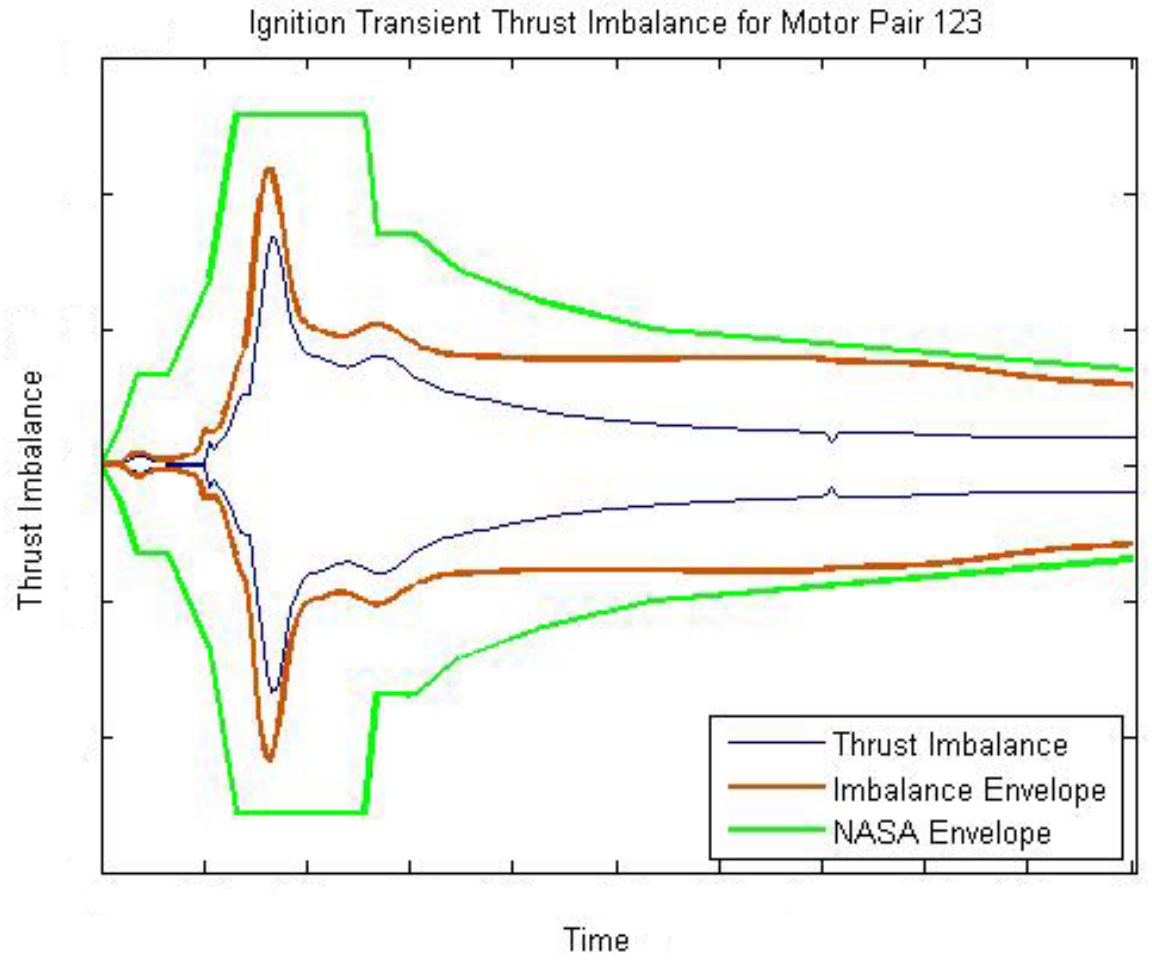

Figure II.6. +/- Absolute value of the thrust imbalance for a single motor pair $\left(\mathrm{PMBT}\right.$ mean $=40^{\circ}-90^{\circ} \mathrm{F}$ and $\left.\mathrm{K}=3.472\right)$.

American Institute of Aeronautics and Astronautics 


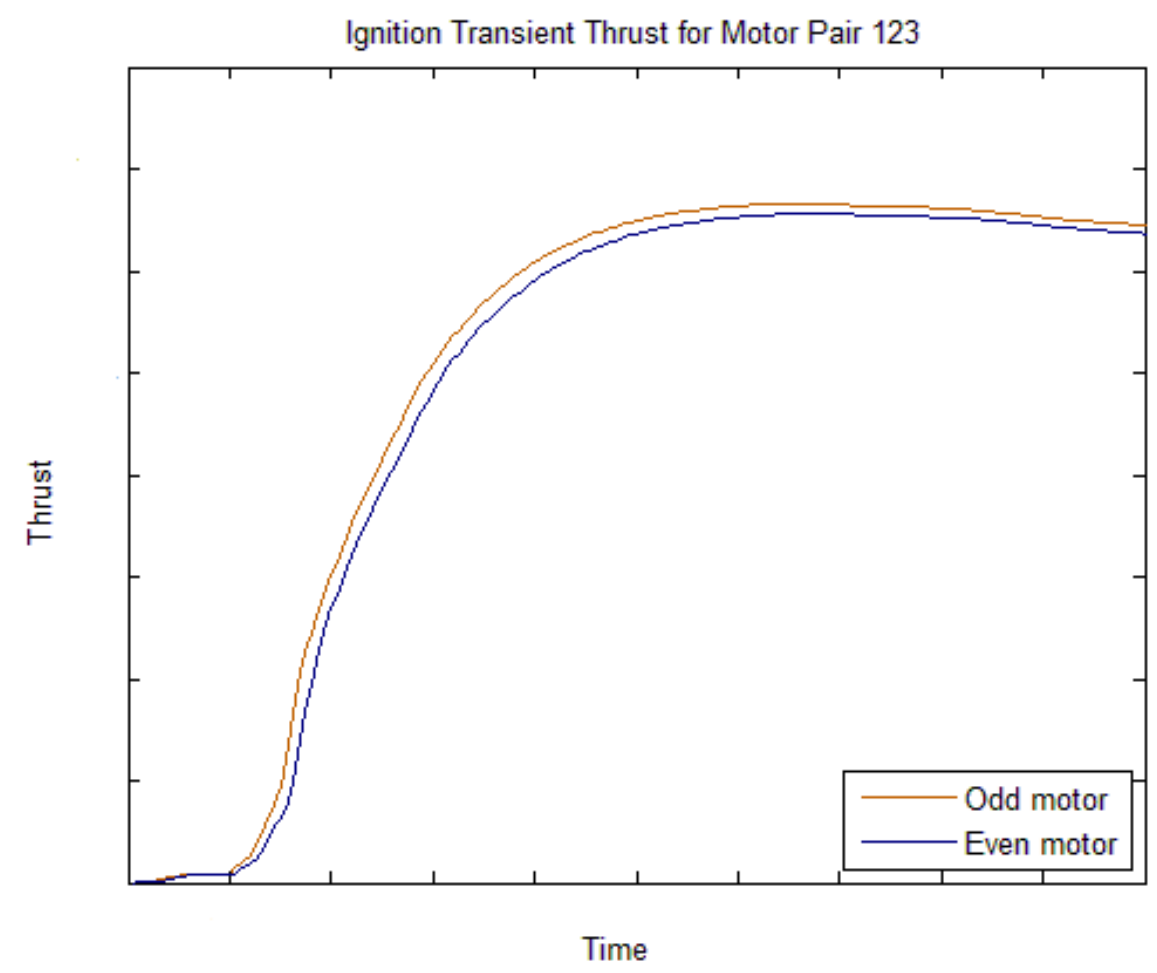

Figure II.7. Thrust time traces for a single motor pair $\left(\mathrm{PMBT}\right.$ mean $\left.=\mathbf{4 0}^{\circ}-\mathbf{9 0}^{\circ} \mathrm{F}\right)$.

\section{Steady State and Tail off Thrust Imbalance Analysis}

The Monte Carlo method described in Ref. 1 was previously used and validated with regard to predicting the thrust imbalance for the Space Shuttle SRM's, as discussed in Refs. 2 and 6 through 17.

The Monte Carlo analysis of the RSRMV thrust imbalance during steady state operation used thirty six selected input variables for the ignition transient code. These variables are presented in Table IV.1 below.

Some of the variables listed in Table III. 1 were held constant for the present analysis, but can be used if their statistical variation properties are known. As can be seen from the variable definitions above, there are motor to motor variations and variations within a single pair of motors. Variations within a pair are identified SHFT after the variable name. For example A1SHFT is the within pair variation of the burn rate coefficient A1. The analysis consisted of selecting input parameters for 20005 -segment RSRMV motors or 1000 motor pairs. The variations between motors of a pair were defined for what was referred to as the odd and even numbered motors in that pair. Specifically, the odd numbered motor was considered the base for the pair and the motor to motor variations were imposed on the even numbered motor relative to the odd numbered motor. 
Table III.1 Monte Carlo Analysis Steady State Operation Variables.

\begin{tabular}{|c|c|}
\hline Variable Name & Variable Definition \\
\hline RHO & propellant Density \\
\hline A1 & burning rate coefficient \\
\hline A1SHFT & reference burn rate coefficient shift between motors of a single pair \\
\hline N1 & burning rate exponent \\
\hline ALPHA & erosive burning rate coefficient \\
\hline BETA & erosive burning rate coefficient \\
\hline ROAL & oxidizer to aluminum ratio \\
\hline$\overline{\mathrm{DE}}$ & exit plane diameter \\
\hline DTI & initial throat diameter \\
\hline THETA & cant angle of the nozzle \\
\hline ALFAN & nozzle cone half-angle \\
\hline $\mathrm{XT}$ & aft end taper dimension \\
\hline $\mathrm{ZO}$ & aft end taper dimension \\
\hline $\mathrm{ZC}$ & aft end taper dimension \\
\hline RONDCN & nozzle end case out of roundness parameter \\
\hline RONDCH & head end case out of roundness parameter \\
\hline RONDGN & nozzle end grain out of roundness parameter \\
\hline RONDGH & head end grain out of roundness parameter \\
\hline EXN & eccentricity in $\mathrm{x}$ at nozzle end \\
\hline EYN & eccentricity in y at nozzle end \\
\hline EXH & eccentricity in $\mathrm{x}$ at head end \\
\hline EYH & eccentricity in y at head end \\
\hline ALPHAH & angular orientation of ovality at nozzle end \\
\hline ALPHAN & angular orientation of ovality at head end \\
\hline ERREF & reference throat erosion rate \\
\hline TGR & grain bulk temperature \\
\hline TGSHFT & reference PMBT difference between motors of a single pair \\
\hline $\mathrm{DO}$ & outside CP grain diameter \\
\hline DI & initial inside CP grain diameter \\
\hline THETAG & aft end taper angle \\
\hline LGCI & initial length of CP propellant grain \\
\hline LGNI & aft end tapered grain length \\
\hline THETCN & nozzle end closure angle \\
\hline THETCH & head end closure angle \\
\hline $\mathrm{RC}$ & propellant star grain outside radius \\
\hline FILL & star valley fillet radius \\
\hline RP & initial radius of truncated star \\
\hline RIS & initial radius at the bottom of the truncated star slot \\
\hline
\end{tabular}

It should be noted at this point that it is important have a good baseline model prediction before applying the statistical procedures used in the analyses described in this paper. To establish that the nominal values for the performance parameters did provide a good baseline using the simplified internal ballistic code described in Refs. 18 and 19, a design optimization program using the same internal ballistics model was used to select the values for the nominal variables which gave the best match to the nominal thrust time trace. This was done using the SLS static test data as a reference thrust time trace and selecting the performance parameters to be used with a pattern search optimization method. The use of this method to match a given thrust time trace has been documented in Refs. 20 and 21. The results of such an analysis are shown in Fig. III-1. 


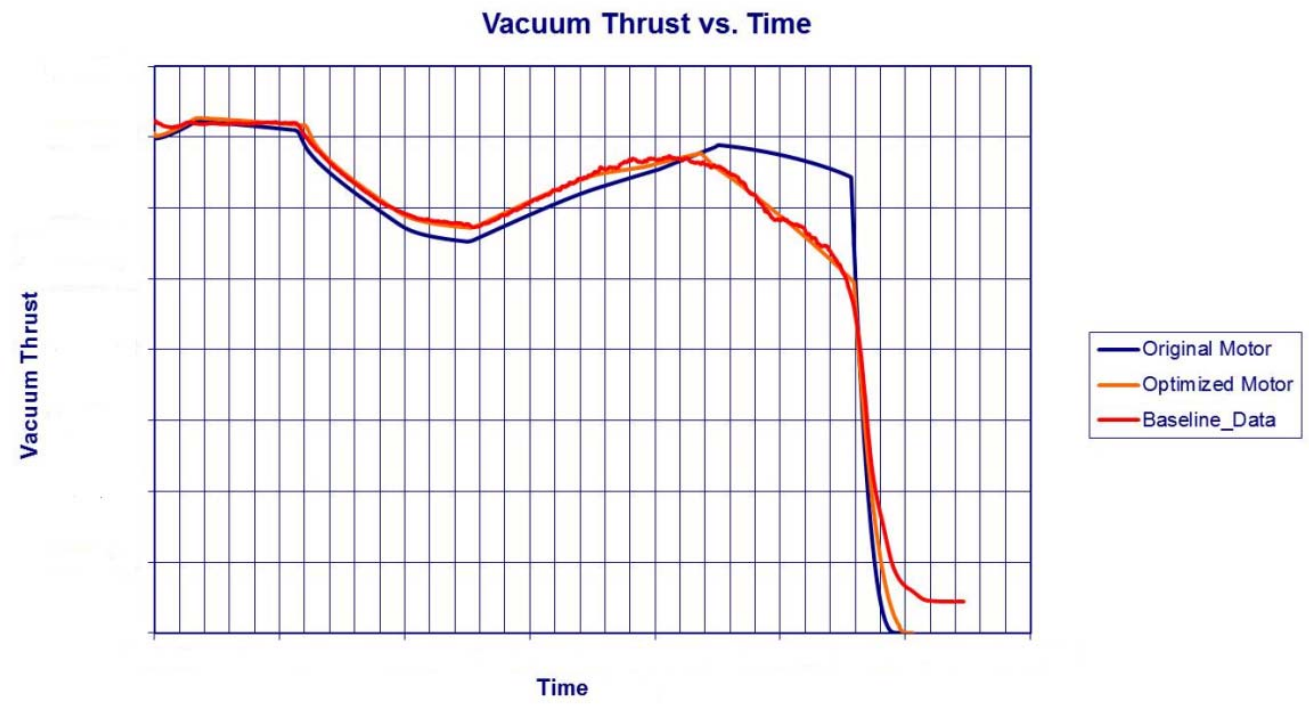

Figure III-1. Results from design optimization program to define a baseline motor.

Based on the Monte Carlo variable selection process, input files for the 2000 individual motors were created. These input files were then analyzed sequentially and individually to determine the thrust time trace for each motor. The results for the odd and even motors were stored separately and the thrust imbalance versus time was calculated for each pair of motors. The thrust imbalance versus time data was analyzed statistically at individual time slices. The results of this analysis were the mean and standard deviation for the thrust imbalance at each time slice chosen. Based on this data a prediction of the K-sigma limit about a zero mean value envelope was constructed as a function time. The same value for $\mathrm{K}$ was used for this analysis as was used for the ignition transient imbalance study described above. This envelope was then compared to the design thrust imbalance limits for a pair of motors during steady state operation. There are two sets of data presented below. One is for the propellant mean bulk temperature (PMBT) of $60^{\circ} \mathrm{F}+/$ - TGSHFT and the other is for a mean value of PMBT selected randomly between $40^{\circ} \mathrm{F}$ and $90^{\circ}$ $\mathrm{F}$ with the same TGSHFT. The $40^{\circ} \mathrm{F}$ to $90^{\circ} \mathrm{F}$ was chosen since it represents the allowable operational range for PMBT. The burn rate reference temperature was $60^{\circ} \mathrm{F}$ for each set of data. Plots for these cases are given Fig. III-2 shows the Monte Carlo prediction envelope for 1000 motor pairs compared to the design specification envelope. The prediction shows values of thrust imbalance which are potentially higher than the design envelope with the peak values occurring slightly earlier in time. Fig III-3 sows the same envelopes with the thrust imbalance versus time for 1000 motor pairs superimposed. The predicted thrust imbalance versus time curves for the 1000 pairs falls well within the both the Monte Carlo prediction and the design envelope. The results for dispersions between motors of a single pair about a mean value of $60^{\circ} \mathrm{F}$ PMBT agree well with the specification limits provided by NASA with regard to the magnitude of the thrust imbalance as a function of time. It can be shown that this same agreement, indeed the same results can be obtained for dispersions about other values of PMBT, assuming that the burn rate reference temperature is the same as the nominal PMBT. The figures also show that the time at which tail off begins for both the predicted and design envelopes are also shown to be in good agreement. Fig. III-4 shows the thrust time traces for all 2000 individual motors and is an indication of the variation in performance for the overall population of motors. Figs. III-5 and III-6 present a comparison of a typical motor pairs thrust imbalance with the envelopes and the thrust time traces for each motor in this pair respectively. 
Thrust Imbalance Envelopes

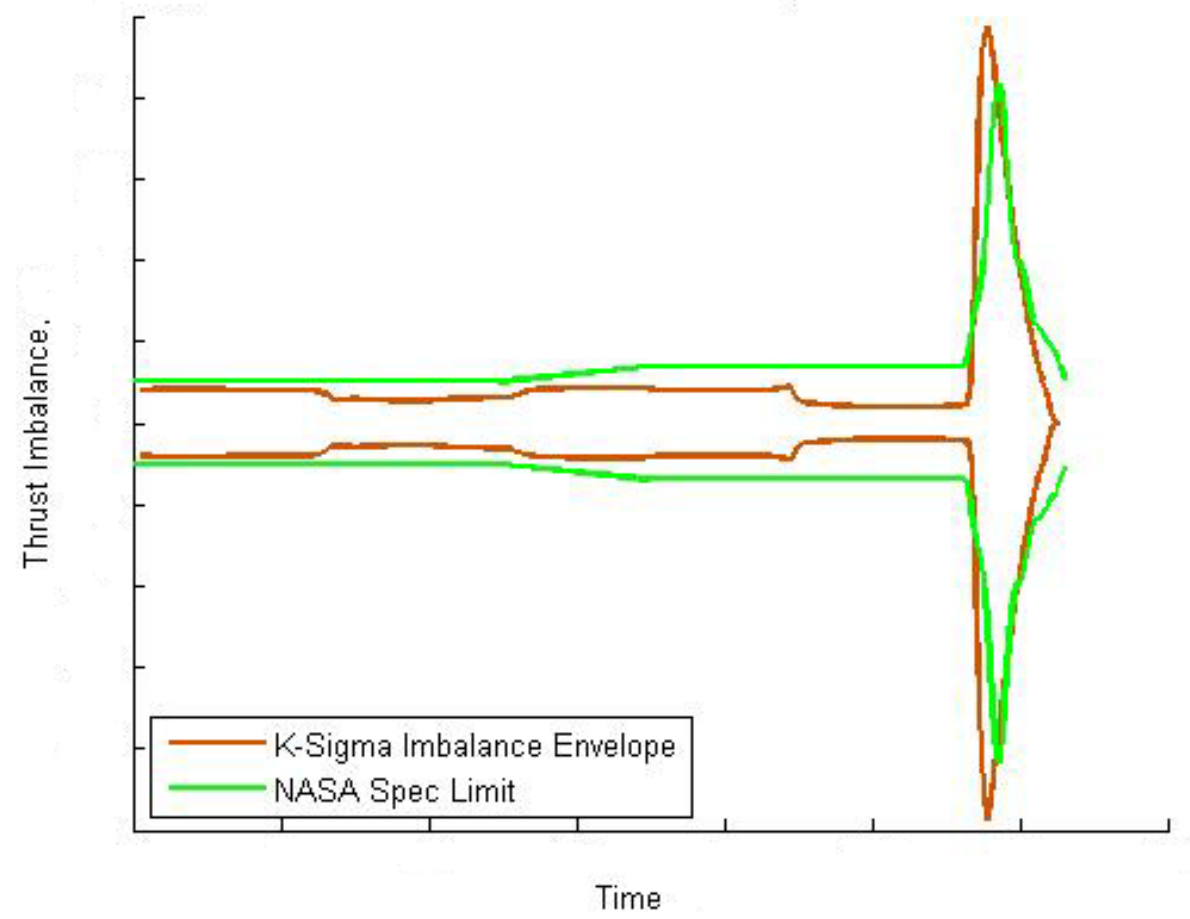

Figure III-2. Steady state thrust imbalance envelopes $\left(\mathrm{PMBT}\right.$ mean $=60^{\circ} \mathrm{F}$ and $\left.\mathrm{K}=3.472\right)$.

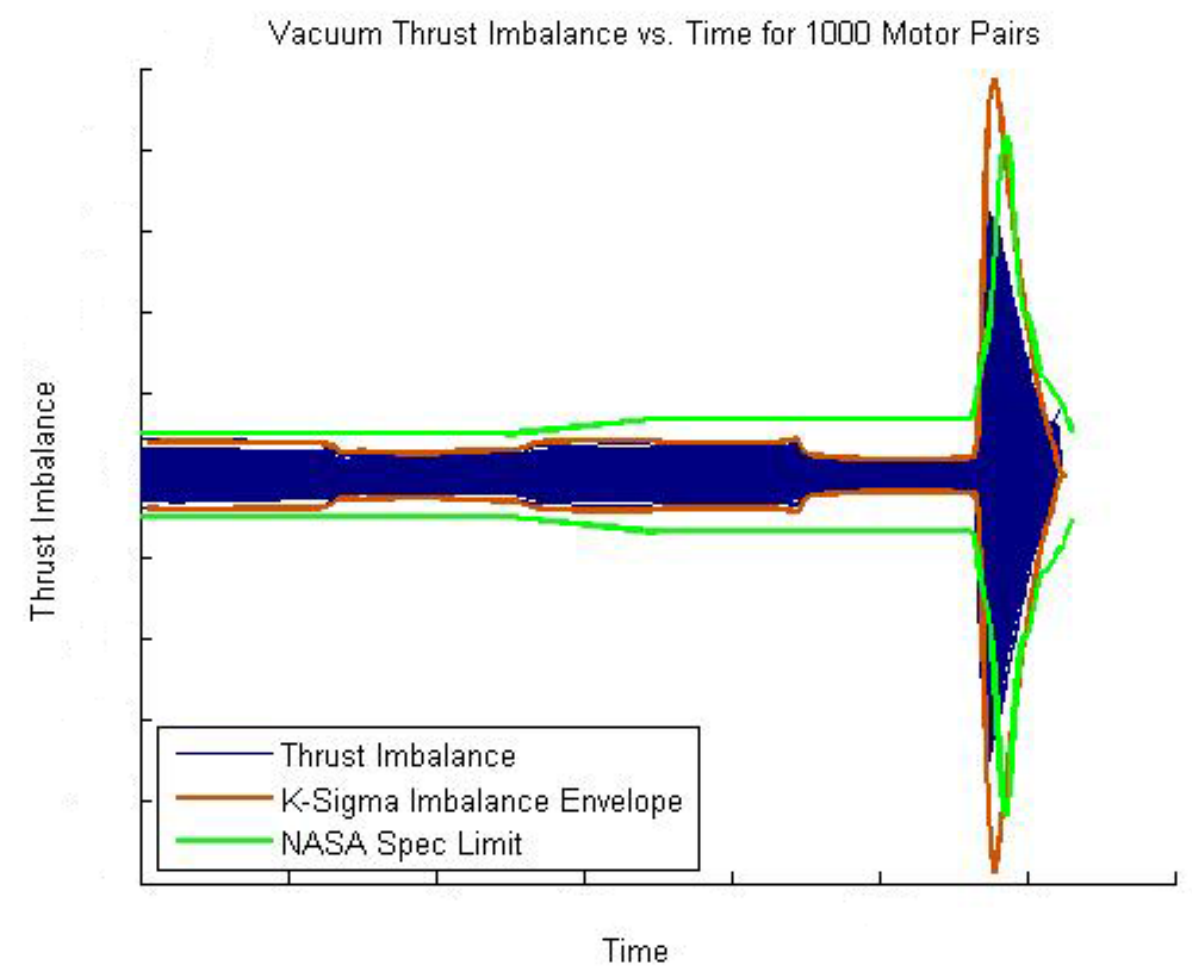

Figure III-3. +/- Absolute value of the steady state thrust imbalance $\left(\mathrm{PMBT}\right.$ mean $=60^{\circ} \mathrm{F}$ and $\left.\mathrm{K}=3.472\right)$.

11

American Institute of Aeronautics and Astronautics 


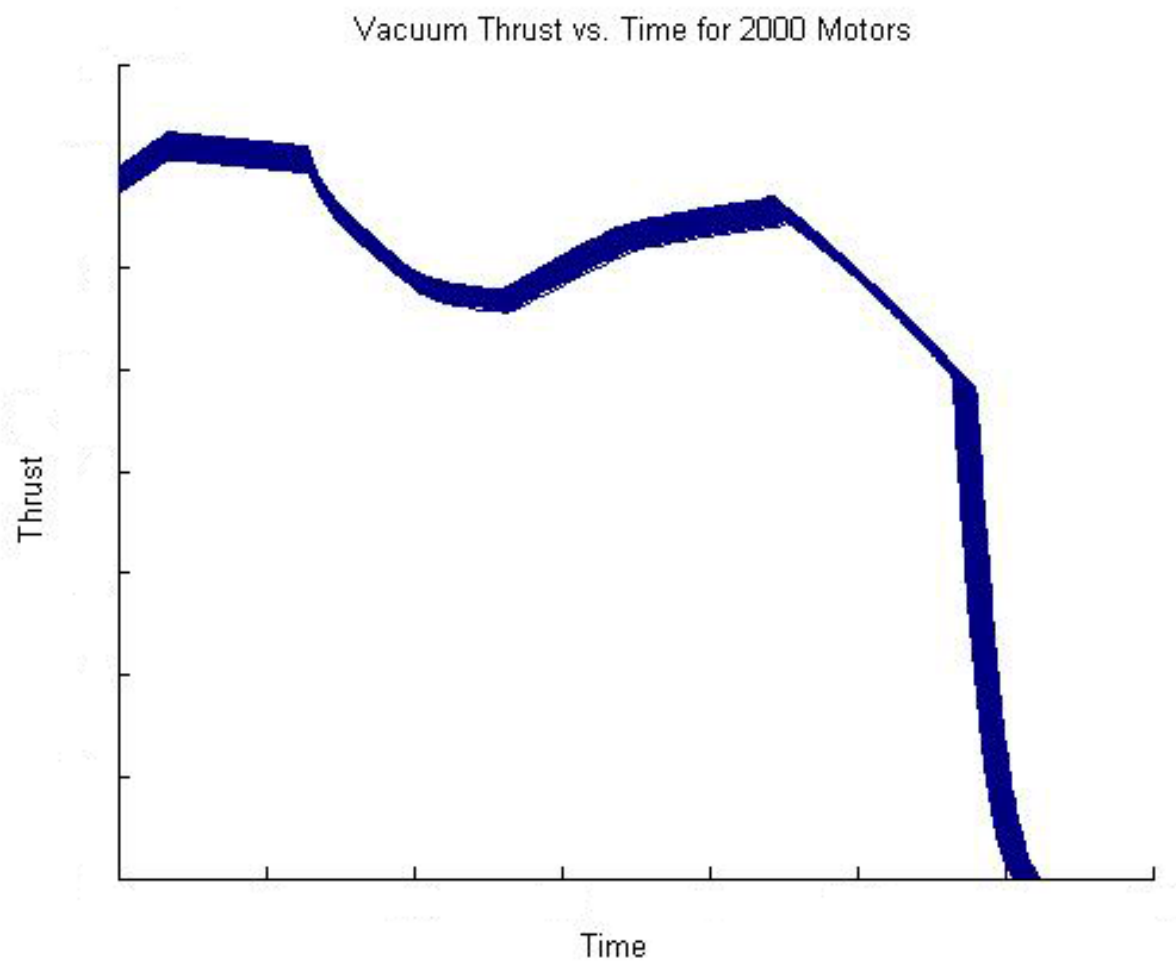

Figure III-4. Thrust time traces for 2000 motors $\left(\right.$ PMBT mean $\left.=60^{\circ} \mathrm{F}\right)$.

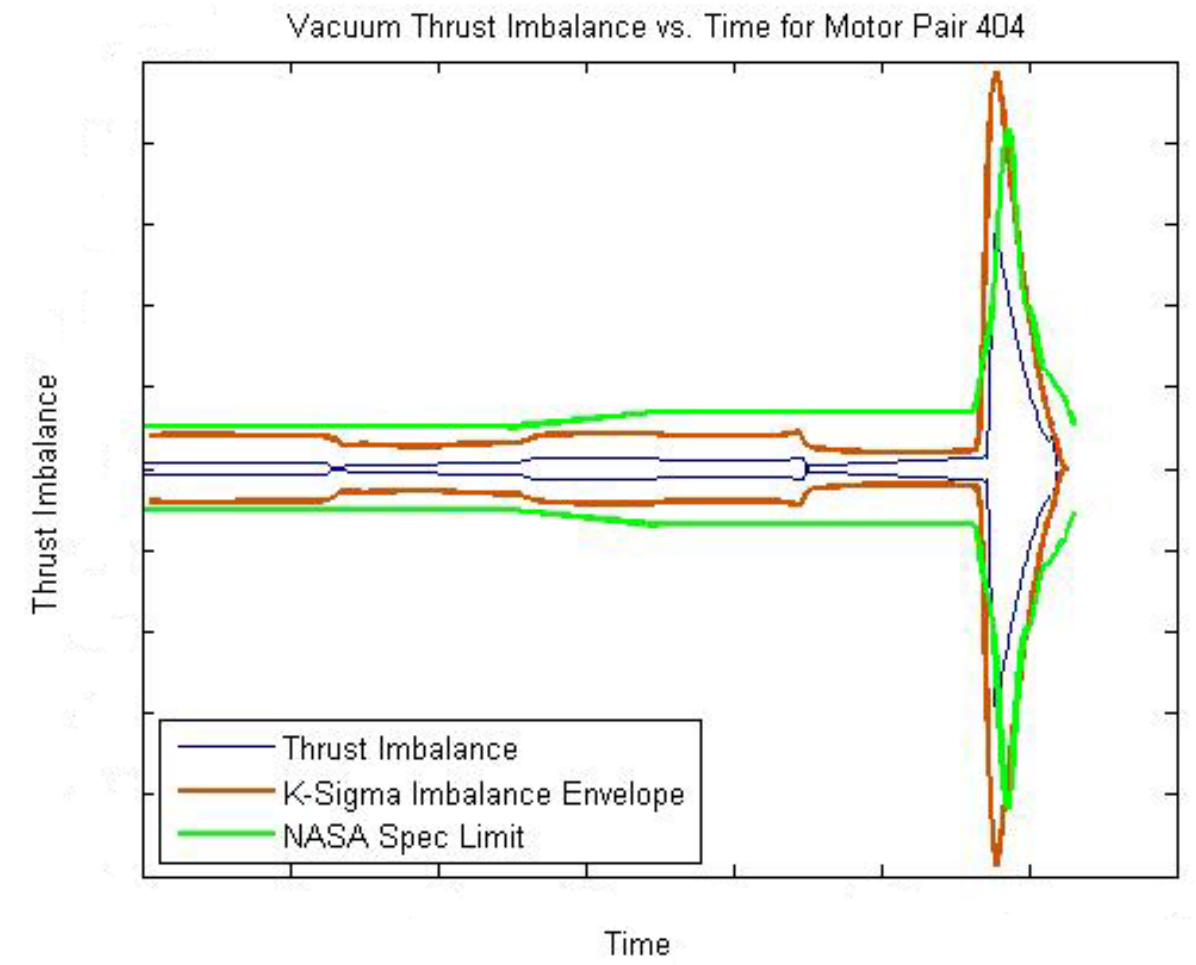

Figure III.5. +/- Absolute value of the thrust imbalance for a single motor pair $\left(\mathrm{PMBT}\right.$ mean $=60^{\circ} \mathrm{F}$ and $\left.\mathrm{K}=3.472\right)$.

American Institute of Aeronautics and Astronautics 


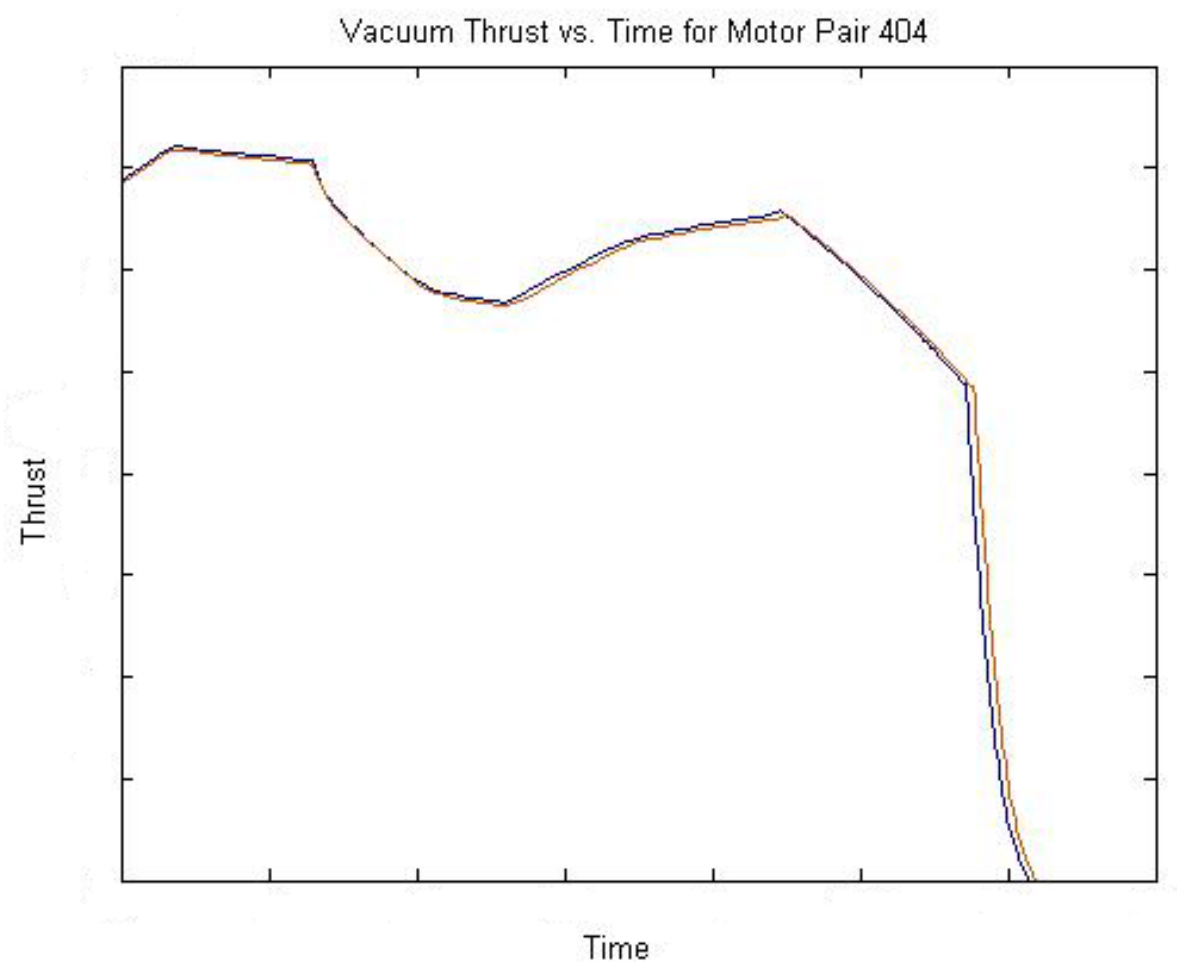

Figure III.6. Thrust time traces for a single motor pair $\left(\mathrm{PMBT}\right.$ mean $\left.=60^{\circ} \mathrm{F}\right)$.

Figs. III-7 through III-11 presents the same type of data as Figs. III-2 through III-6, but for the case where the PMBT is allowed to vary between $40^{\circ}$ and $90^{\circ} \mathrm{F}$ for the odd motor with the same allowable temperature shift between motors of a single pair as was used previously. The reference burn rate temperature is again $60^{\circ} \mathrm{F}$. The thrust imbalance envelopes are similar during the steady state portion of the burn but differ significantly with respect to the tail-off. The time at which the effects of tail-off begin occur are earlier and last for a longer period of time than the previous case when the PMBT was $60^{\circ} \mathrm{F}$. This is an obvious result, but it indicates that the prediction captures accurately the effects of PMBT on the motor burn time. The hotter motors burn out earlier and the colder motors burn out later, hence the wider tail-off region and the spreading out in time of the larger thrust imbalances. Fig. III-7 shows that on average the web action time occurs earlier in time than is shown in the NASA spec limit envelope. And that the maximum thrust imbalance can occur over a wider time range. This is due to the fact that the burn rate reference temperature was maintained at $60^{\circ} \mathrm{F}$ and not changed to the PMBT as was done in developing the NASA spec limit. Hence the results shown in Figs. III-7 through III-11 accounts for the sensitivity of the burn rate to PMBT.

It should be noted that the overall K-Sigma limit is reduced for this case relative to the one with the temperature sensitivity of burn rate removed. This would indicate that the NASA spec limit may be conservative with regard to the magnitude of thrust imbalance, but does not account for the difference in web action times for motors operating at different values of PMBT which are within the operational limits for the motors. It should be noted that the within pair variation of PMBT was the same for each range analyzed. The mean value of the web action time was, as would be expected, strongly dependent on the value of PMBT. 
Thrust Imbalance Envelopes

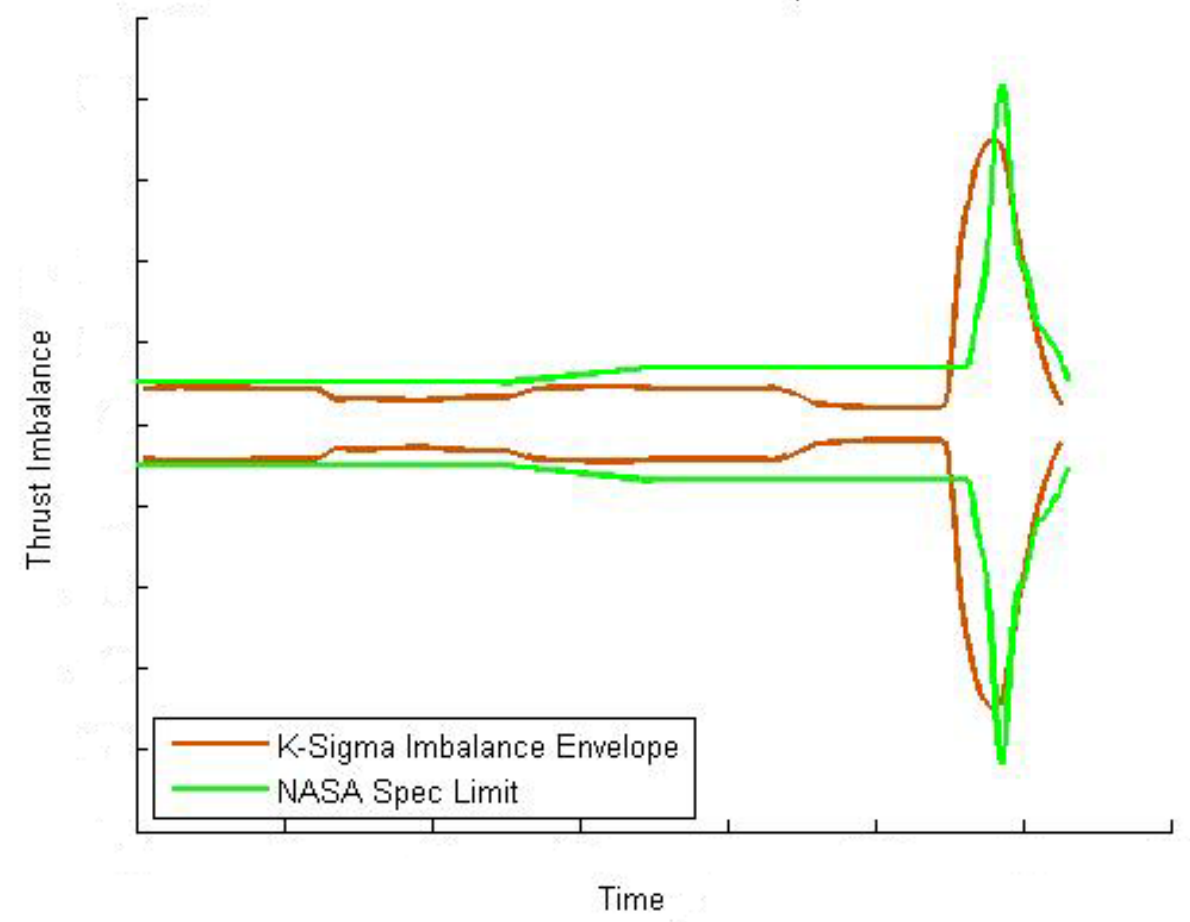

Figure III-7. Steady state thrust imbalance envelopes $\left(\mathrm{PMBT}\right.$ mean $=40^{\circ}-90^{\circ} \mathrm{F}$ and $\left.\mathrm{K}=3.472\right)$.

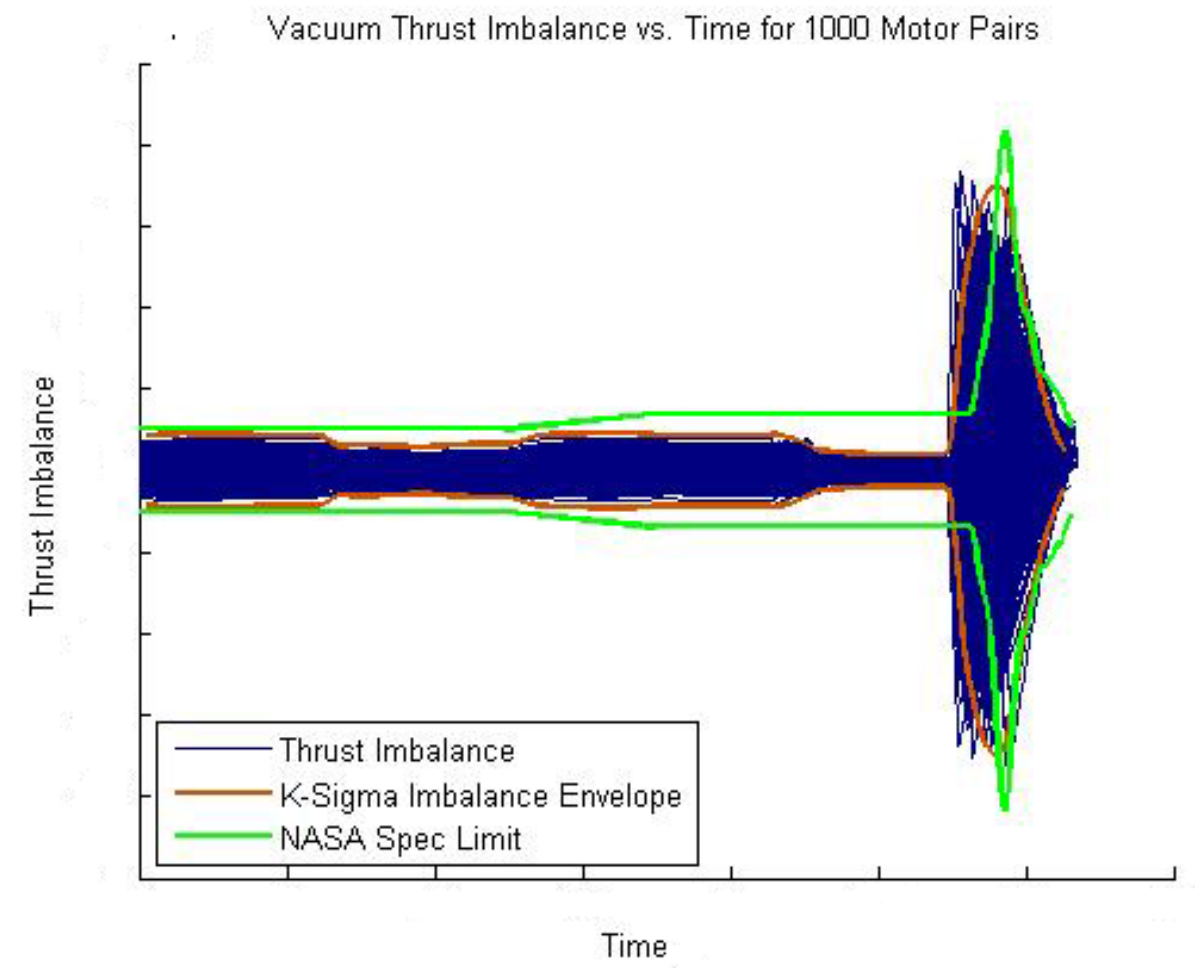

Figure III-8. +/- Absolute value of the steady state thrust imbalance $\left(\mathrm{PMBT}\right.$ mean $=40^{\circ}-\mathbf{9 0}^{\circ} \mathrm{F}$ and $\left.\mathrm{K}=3.472\right)$.

American Institute of Aeronautics and Astronautics 


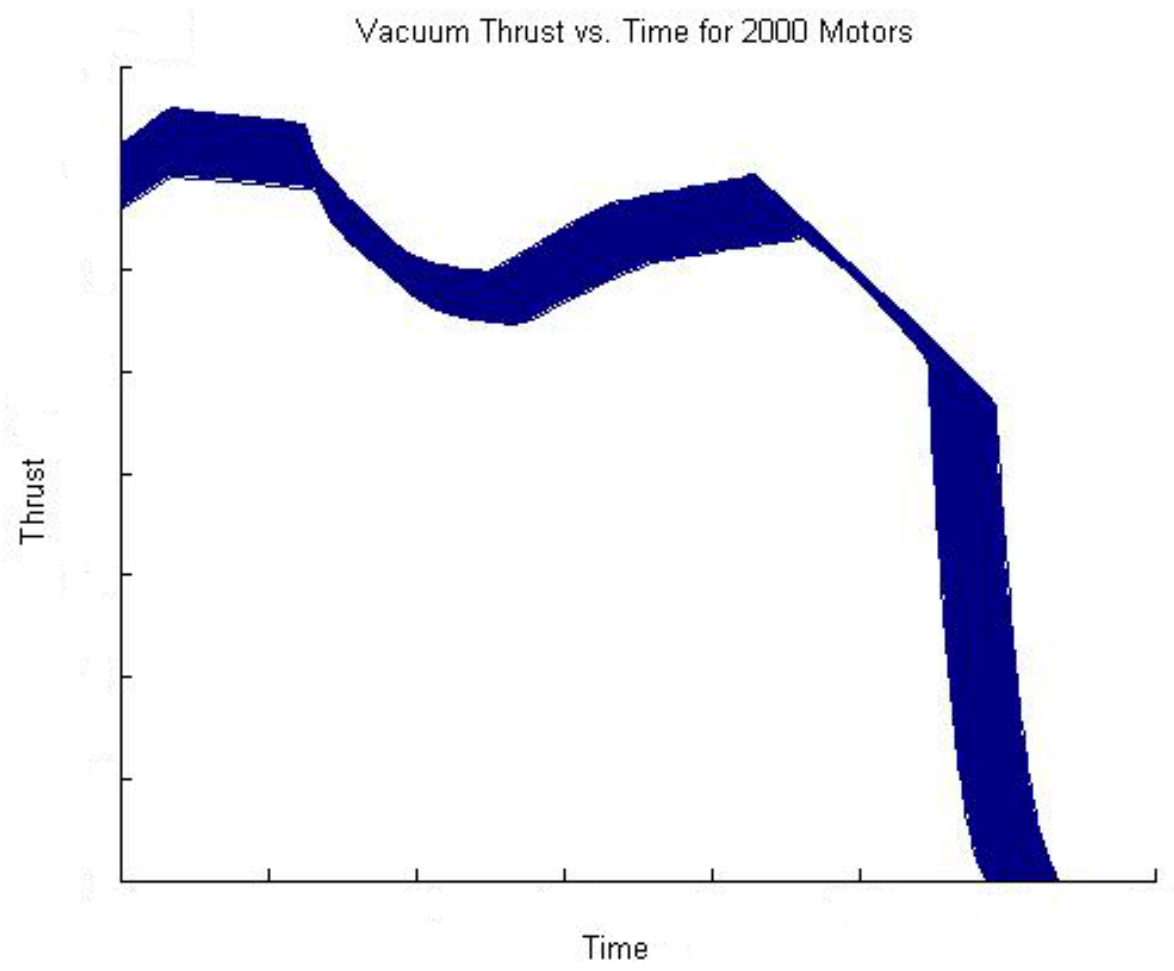

Figure III-9. Thrust time traces for 2000 motors $\left(\right.$ PMBT mean $\left.=40^{\circ}-90^{\circ} \mathrm{F}\right)$.

Vacuum Thrust Imbalance ws. Time for Motor Pair 393

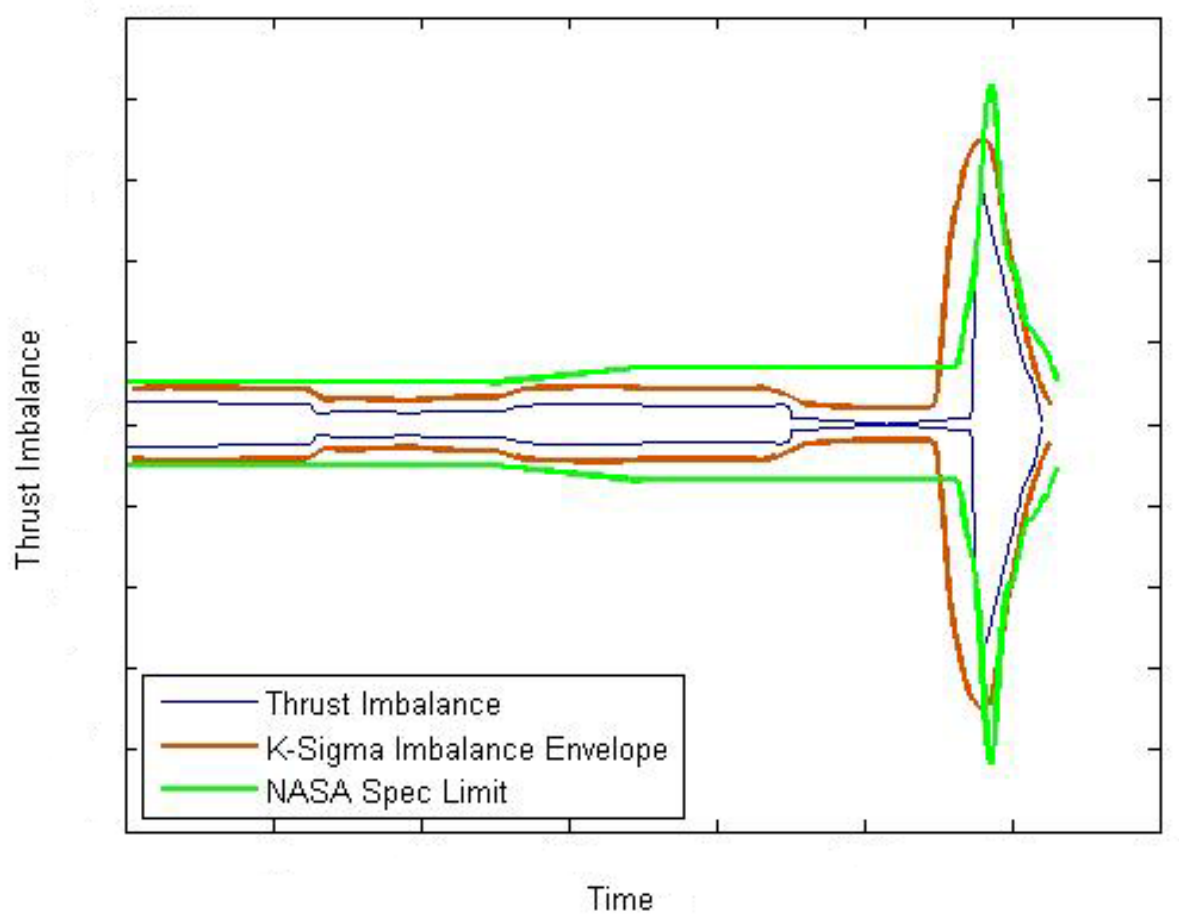

Figure III-10. +/- Absolute value of the thrust imbalance for a single motor pair (PMBT mean $=40^{\circ}-90^{\circ} \mathrm{F}$ and $\left.\mathrm{K}=3.472\right)$. 


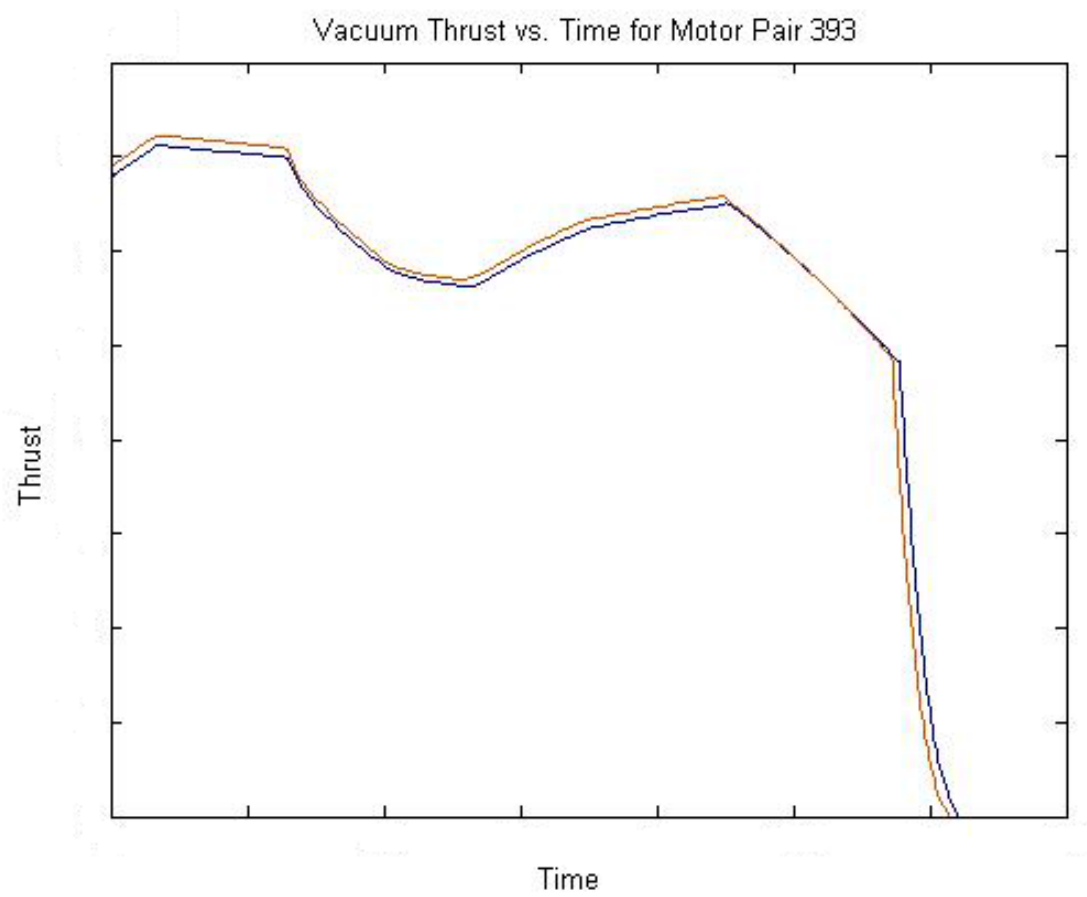

Figure III-11. Thrust time traces for a single motor pair $\left(\mathrm{PMBT}\right.$ mean $\left.=\mathbf{4 0}^{\circ}-\mathbf{9 0}^{\circ} \mathrm{F}\right)$.

To verify that the NASA Spec Limit was independent of PMBT, an analysis using $90^{\circ} \mathrm{F}$ for mean PMBT with a $90^{\circ} \mathrm{F}$ burn rate reference temperature was also analyzed. The results for the thrust imbalance and web action times were identical with those above for the $60^{\circ} \mathrm{F}$ case described above and are shown in Figs. III-12 and III-13 below.

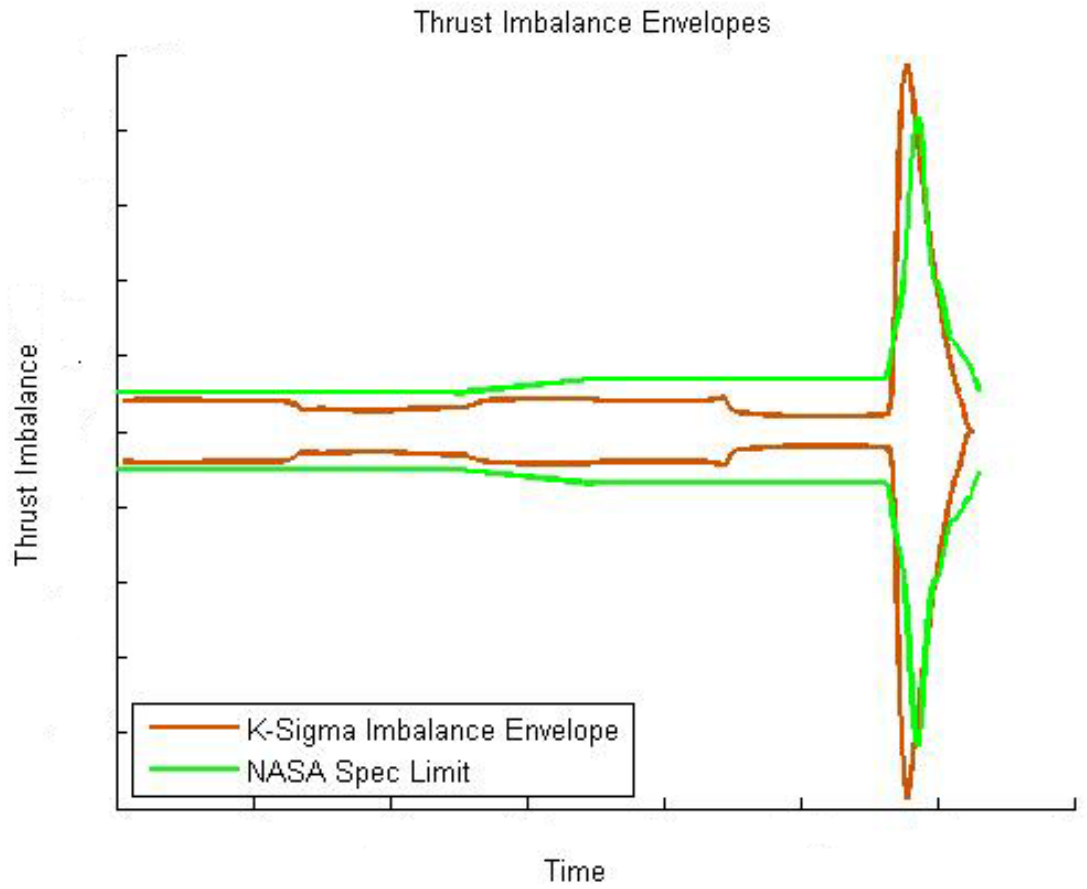

Figure III-12. Steady state thrust imbalance envelopes $\left(\mathrm{PMBT}\right.$ mean $=90^{\circ} \mathrm{F}$ and $\left.\mathrm{K}=3.472\right)$. 


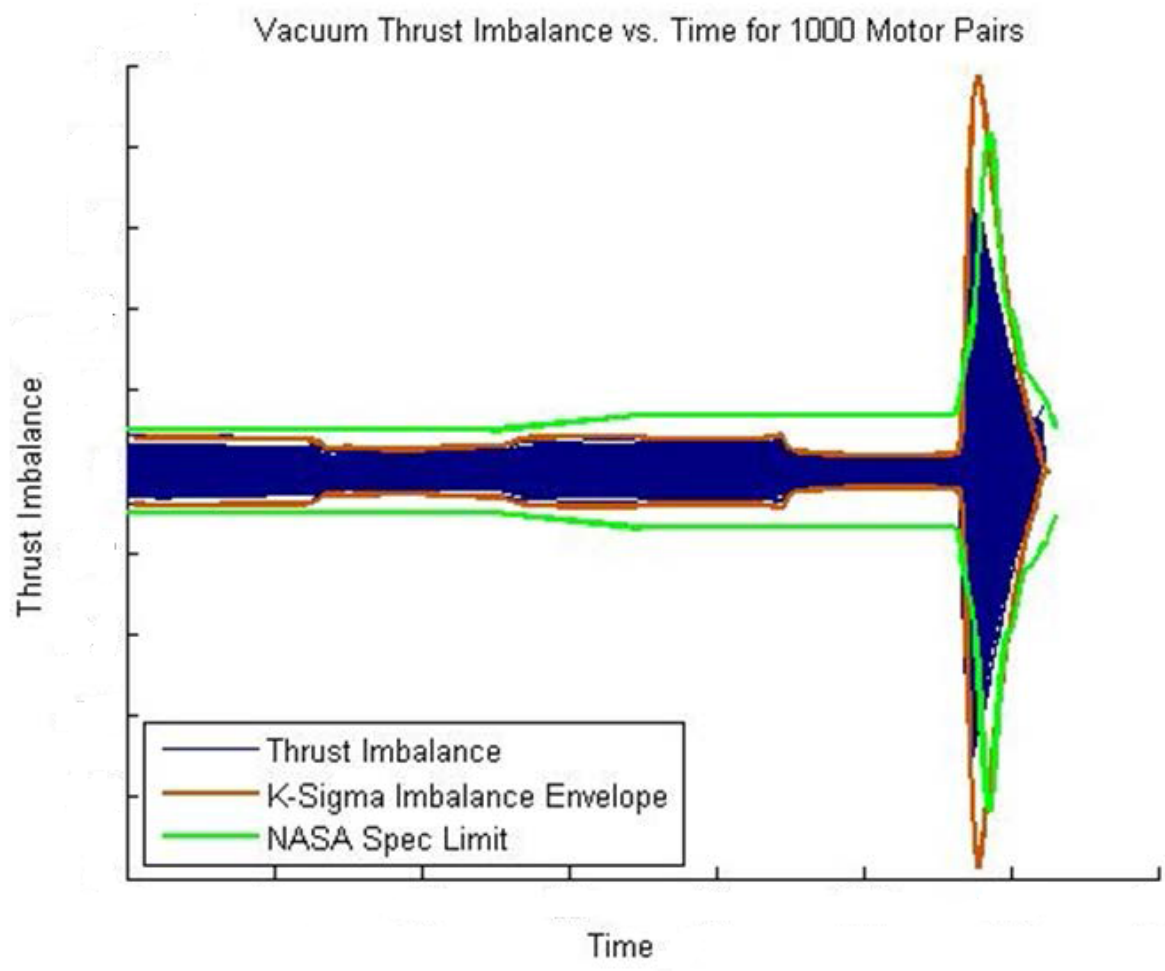

Figure III-13. +/- Absolute value of the steady state thrust imbalance $\left(\mathrm{PMBT}\right.$ mean $=90^{\circ} \mathrm{F}$ and $\left.\mathrm{K}=3.472\right)$.

\section{Summary}

Two existing legacy solid rocket motor internal ballistics codes, one for the ignition transient and one for the steady state and tail-off periods of operation have been interfaced with a Monte Carlo statistical program to predict the thrst imbalance between pairs of solid rocket motors to be used on the SLS vehicle. The thrust imbalance envelopes generated by the current analysis are in general agreement with the design specification requirements for the SLS vehicle during the ignition transient and the steady state and tail-off periods of operation.

\section{References}

\footnotetext{
${ }^{1}$ Sforzini, R. H., Foster, W. A., Jr. and Johnson, J. S., "A Monte Carlo Investigation of Thrust Imbalance of Solid Rocket Motor Pairs," submitted to NASA/George C. Marshall Space Flight Center, Huntsville, Alabama, NASA CR-120700, November, 1974.

${ }^{2}$ Foster, W. A., Jr., Sforzini, R. H. and Shackelford, B. W., Jr., "Thrust Imbalance of the Space Shuttle Solid Rocket Motors," Journal of Spacecraft and Rockets, Vol. 19, No. 6, 1982.

${ }^{3}$ Caveny, L. H. and Kuo, K. K., "Ignition Transients of Large Segmented Solid Rocket Motors," NASA CR-150162, April, 1976.

${ }^{4}$ Caveny, L. H., "Extensions to Analysis of Ignition Transients of Segmented Rocket Motors," NASA CR-150638, January, 1978.

${ }^{5}$ Foster, W. A., Jr. and Crowder, W., "Solid Rocket Booster Ignition and Steady-State Thrust Imbalance," submitted to NASA/George C. Marshall Space Flight Center, Huntsville, Alabama, September 6, 2012.
} 
${ }^{6}$ Eisenhart, C., Hastay, M. W. and Wallis, W. A., Techniques of Statistical Analysis, $1^{\text {st }}$ Edition, McGraw-Hill Book Company, New York, 1947.

${ }^{7}$ Sforzini, R. H. and Foster, W. A., Jr., "Monte Carlo Investigation of Thrust Imbalance of Solid Rocket Motor Pairs," Journal of Spacecraft and Rockets, Vol. 13, No. 4, 1976.

${ }^{8}$ Sforzini, R. H. and Foster, W. A., Jr., "Effects of Solid-Propellant Temperature Gradients on the Internal Ballistics of the Space Shuttle," Journal of Spacecraft and Rockets, Vol. 16, No. 3, 1979.

${ }^{9}$ Foster, W. A., Jr., Sforzini, R. H. and Shu, P. H., "Flight Thrust Imbalance of Space Shuttle SRM Boosters," Journal of Propulsion and Power, Vol. 5, No. 2, 1989.

${ }^{10}$ Sforzini, R. H., Foster, W. A., Jr. and Shackelford, B. W., "Effects of Solid-Propellant Temperature Gradients on the Internal Ballistics of the Space Shuttle," AIAA/SAE 14th Joint Propulsion Conference, Las Vegas, Nevada, July, 1978.

${ }^{11}$ Foster, W. A., Jr., Sforzini, R. H. and Shackelford, B. W., "Thrust Imbalance of the Space Shuttle Solid Rocket Motors," AIAA/SAE/ASME 17th Joint Propulsion Conference, Colorado Springs, Colorado, July, 1981

${ }^{12}$ Foster, W. A., Jr., Sforzini, R. H. and Shu, P. H., "Thrust Imbalance of Solid Rocket Motor Pairs on Space Shuttle Flights," 22nd AIAA/SAE/ASME/ASEE Joint Propulsion Conference, Huntsville, Alabama, June, 1986. ${ }^{3}$ Caveny, L. H. and Kuo, K. K., "Ignition Transients of Large Segmented Solid Rocket Motors," NASA CR-150162, April, 1976.

13 Sforzini, R. H. and Foster, W. A., Jr., "Solid-Propellant Rocket Motor Ballistic Performance Variation Analysis," submitted to NASA/George C. Marshall Space Flight Center, Huntsville, Alabama, NASA CR-144264, September, 1975.

${ }^{14}$ Sforzini, R. H. and Foster, W. A., Jr. and Murph, J. E., "Solid-Propellant Rocket Motor Ballistic Performance Variation Analysis (Phase Three)," submitted to NASA/George C. Marshall Space Flight Center, Huntsville, Alabama, NASA CR-150577, November, 1977. ${ }^{6}$ Sforzini, R. H. and Foster, W. A., Jr., "Monte Carlo Investigation of Thrust Imbalance of Solid Rocket Motor Pairs," Journal of Spacecraft and Rockets, Vol. 13, No. 4, 1976.

${ }^{15}$ Sforzini, R. H. and Foster, W. A., Jr. and Murph, J. E., "Solid-Propellant Rocket Motor Ballistic Performance Variation Analysis (Phase Three)," submitted to NASA/George C. Marshall Space Flight Center, Huntsville, Alabama, NASA CR-150577, November, 1977.

${ }^{16}$ Sforzini, R. H. and Foster, W. A., Jr. and Murph, J. E., "Solid-Propellant Rocket Motor Ballistic Performance Variation Analysis (Phase Four)," submitted to NASA/George C. Marshall Space Flight Center, Huntsville, Alabama, January, 1979.

${ }^{17}$ Foster, W. A., Jr. and Sforzini, R. H., "Final Report: Solid Rocket Motor Internal Ballistic Variations," Vol. I, submitted to NASA/George C. Marshall Space Flight Center, Huntsville, Alabama, March, 1982.

${ }^{18}$ Foster, W. A., Jr., Sforzini, R. H., Shu, P. H., Conover, G. A. and Langhenry, M. T., "Final Report: Solid Rocket Motor Internal Ballistic Variations," Vol. II, submitted to NASA/George C. Marshall Space Flight Center, Huntsville, Alabama, June, 1984.

19 Sforzini, R. H., "Design and Performance Analysis of Solid-Propellant Rocket Motors Using a Simplified Computer Program," NASA CR-129025, October, 1972.

${ }^{20}$ Sforzini, R. H., "Extension of a Simplified Computer Program for Analysis of Solid-Propellant Rocket Motors," NASA CR-129024, April, 1973.

${ }^{21}$ Sforzini, R. H., "Automated Approach to Design of Solid Rocket Motors," Journal of Spacecraft and Rockets, Vol. 18, No. 3, 1981.

${ }^{22}$ Foster, W. A., Jr., "Off Design Performance and Variation Analysis," submitted to NASA/George C. Marshall Space Flight Center, Huntsville, Alabama, March 2011, 2011. 